\title{
Importancia de promover la redacción conjunta de recomendaciones sobre indicaciones y uso de exámenes de imagenología en ginecología: un paso en Chile hacia el choosing wisely
}

En el año 2012 la ABIM foundation (Fundación de la Junta Americana de Medicina Interna) lanzó la campaña 'choosing wisely' (eligiendo o escogiendo sabiamente). Originalmente esta iniciativa buscaba promover la conversación entre proveedores de salud y pacientes sobre el sobreuso o mal uso de algunos test o procedimientos diagnósticos. La idea era promover la elección juiciosa del método diagnóstico más adecuado para una situación determinada y no solicitar exámenes basado en la inquietud del paciente, o por temor a ser demandado por negligencia o error médico, o para reafirmar un diagnóstico per se ya evidente por parte del clínico. Así se evitaba solicitar exámenes de más, innecesarios o eventualmente inútiles para el proceso diagnóstico de un caso particular y que sólo contribuyen a encarecer el costo de la prestación médica (1).

En el año 2014, la Robert Wood Johnson Foundation publicó los resultados de una encuesta realizada a médicos norteamericanos donde se abordaba la temática: Estudios y procedimientos innecesarios en los sistemas de atención en salud. Qué opinan los médicos del problema, de sus causas o de sus soluciones. Este estudio mostró que tres cuartos $(73 \%)$ de los médicos opinaba que la solicitud de exámenes innecesarios era un problema muy $(29 \%)$ o de cierta forma serio $(44 \%)$ en la comunidad de prestadores. Junto a ello, el estudio mostró que aproximadamente $72 \%$ de los médicos sentía que el médico promedio pedía un examen innecesario al menos 1 vez por semana. Además que los médicos no especialistas tiende a pedir más exámenes innecesarios que la contraparte especialista $(40 \%$ vs $24 \%)$. La solicitud aumenta cuando se enfrenta a un paciente insistente y ansioso por hacerse un examen. Que la solicitud además depende de la experiencia y número de pacientes que ve un médico por semana. Desde la perspectiva médica tres son las mayores razones para pedir un examen innecesario. El miedo al juicio por mala práctica médica (52\%), como una forma de sentirse más seguro $(36 \%)$ o simplemente para confirmar su diagnóstico $(30 \%)$. Otros factores que influyen en la solicitud son la insistencia del paciente ansioso $(28 \%)$ y para tranquilizar o hacer feliz al paciente $(23 \%)$. Menos comúnmente, las razones son no tener tiempo suficiente para ver y examinar al paciente $(13 \%)$, el pago por examen $(5 \%)$ y la aparición de nueva tecnología (5\%). En este mismo estudio, los médicos señalaron que la primera responsabilidad en solucionar este problema la tienen los médicos y que una forma de reducir la solicitud innecesaria de exámenes es contar con guías clínicas o recomendaciones basadas en la evidencia. De hecho, la encuesta mostró que cuando los médicos conocen de la iniciativa choosing wisely, conocen de las recomendaciones, tienden a conversar más con los pacientes y a reducir la solicitud de exámenes inadecuados para un caso o innecesarios (2).

Basado en esta encuesta, la ABIM llamó a los distintos organismos de salud, sociedades científicas y entes no médicos a identificar exámenes o procedimientos comúnmente solicitados innecesariamente en su área de desempeño. Desde ese momento más de 300 recomendaciones para médicos y pacientes han sido publicadas, todas las cuales están disponibles en el website http://www. choosingwisely.org/.

En Obstetricia y Ginecología, múltiples son las situaciones en las cuales como médicos nos vemos enfrentados a la solicitud de exámenes o procedimientos innecesarios. A modo de ejemplo, la solicitud de ultrasonografía para tamizaje de patología ovárica o uterina en pacientes asintomáticas (donde la evidencia actual no ha mostrado beneficio en reducir la mortalidad por cáncer), la toma de citología cervical o test de VPH (virus papiloma humano) en mujeres menores de 20 a 25 años (donde la prevalencia de 
infección transitoria por VPH es alta, la frecuencia de lesiones preinvasoras $\geq$ NIE III es baja y el estudio colposcópico y biópsico aumenta el riesgo de sobre tratamiento innecesario), la solicitud de ultrasonografía 3D para la evaluación fetal, la solicitud estándar de exámenes preoperatorios en mujeres jóvenes sanas y de bajo riesgo quirúrgico, la indicación de inducción electiva sin causa materna o fetal, la cesárea a libre demanda, entre otras. Todas esas decisiones aumentan el costo de atención, pueden determinar procesos diagnósticos y tratamientos innecesarios, indebidos y, más complejo aún, que pueden tener complicaciones. En este sentido distintas sociedades científicas $u$ organismos colegiados como ACOG (American College of Obstetricians and Gynecologists), SGO (Society of Gynecologic Oncologists), ACR (American College of Radiologists), ASMR
(American Society of Reproductive Medicine) se han sumado a la iniciativa y han comenzado a definir recomendaciones universales que buscan reducir este problema.

En la Tabla I se listan 5 recomendaciones actualmente promovidas por ACOG y que han sido apoyadas por la iniciativa choosing wisely y más importante aún por la comunidad (3).

En la Tabla II se listan las recomendaciones de la sociedad de ginecólogos oncólogos (SGO) apoyadas por la iniciativa choosing wisely.

En la Tabla III se indica una recomendación útil para los ginecólogos por parte del colegio americano de radiólogos (ACR) y adoptadas por choosing wisely.

En la Tabla IV se indican recomendaciones de la sociedad americana de medicina reproductiva (ASRM) y adoptadas por choosing wisely.

\section{Tabla I \\ RECOMENDACIÓN AMERICAN COLLEGE OF OBSTETRICIANS AND GYNECOLOGISTS (ACOG)}

1. No hacer tamizaje (CA125 y/o ultrasonografía transvaginal) para cáncer de ovario en mujeres asintomáticas con riesgo población promedio.

2. No tratar la displasia leve (NIE I) que tenga menos de 2 años de evolución o persistencia. Para la mayoría de las mujeres se trata de una infección transitoria por VPH que remitirá espontáneamente antes de 12 meses, por tanto para la mujer promedio no requiere tratamiento.

3. No realizar citología cervical anual en mujeres entre 30 y 65 años. El tamizaje anual no muestra beneficio adicional sobre el intervalo cada 3 años. Esta recomendación no exime a la paciente del examen pélvico anual.

4. No indicar inducciones electivas sin causa médica de interrupción entre las 39 y 41 semanas a menos que el cuello uterino esté evidentemente maduro y favorable.

5.- No indicar cesárea electiva (sin indicación médica) antes de las 39 semanas

Tabla II

RECOMENDACIONES SOCIEDAD GINECÓLOGOS ONCÓLOGOS (SGO)

1. No retardar la derivación a cuidados paliativos de una paciente con cáncer avanzado o recurrente que lo amerita y necesita.

2. Evitar el uso rutinario de imágenes durante el seguimiento de pacientes con cánceres ginecológicos (en ausencia de síntomas y/o elevación de marcadores). Tal conducta no ha demostrado impacto en detectar más precozmente la recurrencia o en mejorar la sobrevida.

3. No hacer citología cervical de seguimiento en pacientes tratadas por cáncer de endometrio. No aumenta la detección de recurrencias locales. Una citología alterada puede conllevar estudio innecesario (colposcopia y biopsia) y no conducente.

4. No realizar colposcopia a pacientes tratadas por cáncer de cuello que tienen citología cervical informada como NIE I, salvo que tengan lesión visible.

5. No hacer tamizaje de cáncer de ovario (CA125 y/o ultrasonografía) en mujeres con riesgo bajo. 


\section{Tabla III RECOMENDACIÓN DEL COLEGIO AMERICANO DE RADIÓLOGOS (ACR)}

1. No hacer seguimiento de quistes anexiales de aspecto benigno o sin importancia. Quistes simples o hemorrágicos en mujeres en edad reproductiva son casi siempre fisiológicos.

2. En la mujer postmenopáusica, un quiste simple habitualmente no tiene importancia. Después de una buena ultrasonografía, un quiste simple menor de $5 \mathrm{~cm}$ en una mujer en edad reproductiva no amerita seguimiento. En la postmenopausia, un quiste simple menor de $1 \mathrm{~cm}$ tampoco.

Tabla IV

\section{RECOMENDACIONES DE LA SOCIEDAD AMERICANA DE MEDICINA REPRODUCTIVA (ASRM)}

1. No medir niveles de FSH en mujeres menores de 40 años en la búsqueda de transición a la menopausia basada en sangrado uterino anormal.

2. No solicitar cariotipo como parte del estudio inicial de la amenorrea.

3. No solicitar estudio inmunológico como parte de la evaluación rutinaria de la infertilidad.

4. No solicitar estudio de trombofilias como parte de la evaluación rutinaria de la paciente infértil.

5. No realizar test postcoital como parte del estudio de infertilidad.

6. No hacer laparoscopia diagnóstica de rutina para el estudio de la infertilidad de causa no explicada.

Para la Sociedad Chilena de Obstetricia y Ginecología se hace un deber y un compromiso ineludible el promover la iniciativa choosing wisely y el dar a conocer algunas de las recomendaciones propuestas por otras entidades relacionadas con nuestra práctica. No cabe duda que avanzar en dicho camino contribuirá a entregar un mejor cuidado y más racional a nuestras pacientes.

En este sentido, queremos destacar el artículo que aparece en el presente número de la revista, donde ginecólogos y radiólogos nacionales se han unido en una iniciativa que permite orientar a los ginecólogos y obstetras, médicos generales y alumnos en formación sobre las indicaciones, ventajas y desventajas que tienen los distintos métodos imagenológicos en la evaluación de la patología benigna que afecta a la mujer. Para nuestro conocimiento, este es el primer trabajo, sobre esta temática, donde médicos de ambas áreas escriben en forma colaborativa un artículo, en español, que permita orientarnos en la selección e indicación de la ultrasonografía transvaginal, la tomografía axial computarizada y la resonancia magnética. Resulta relevante la concordancia de opinión en que una buena ultrasonografía hecha por un médico entrenado, idealmente transvaginal, será la primera y más costo efectiva herramienta para el estudio de la mayoría de las patologías. Sin embargo, existen condiciones donde la solicitud repetida de ecografías no aporta en aumentar la probabilidad diagnóstica y ésta debe ser reemplazada por alguno de los otros métodos. Que no necesariamente una ultrasonografía debe ser seguida por una tomografía y que a veces la resonancia puede ser más útil que los otros métodos (4).

Queremos motivar a nuestros especialistas a informarse sobre la iniciativa choosing wisely, a conocer de las recomendaciones existentes y a cuestionarse cada vez que pidan un examen. ¿Realmente se justifica, me aporta y no encarece innecesariamente el manejo que le ofrezco a mi paciente?

Debemos promover que continuamente surjan cuestionamientos a lo que hacemos o que se obtengan los fundamentos o validación para una determinada práctica, que por muy obvia, efectiva o arraigada que esté entre nosotros no necesariamente se justifica mantener. Esta decisión no significa una crítica o autodestrucción a lo que hacemos bien sino un fomento al espíritu de mejora continua del cual siempre debemos velar.

Dr. Mauricio Cuello Fredes Presidente de SOCHOG Profesor Asociado División Obstetricia y Ginecología Pontificia Universidad Católica de Chile 


\section{REFERENCIAS}

1. Choosingwisely, an initiative of the ABIM Foundation: About the campaign. F62-11-2015. Disponible en: www.abimfoundation.org.

2. Unnecessary tests and procedures in the health care system. What physicians say about the problem, the causes and the solutions: results from a national survey of Physicians. ABIM Foundation, sponsored by the Robert Wood Johnson Foundation, Mayo 2014.
3. Five things physicians and patients should question. Choosingwisely, ACOG, Febrero 2013. Disponible en ACOG website (www.acog.org).

4. Huete A, Craig J, Vial M, Farías M, Tsunekawa $H$, Cuello M. Rol de la imagenología en el proceso diagnóstico de la patología ginecológica benigna. Rev Chil Obstet Ginecol 2016;81(1):63-85. 